\title{
Climate Change and Emergence of violent Conflicts
}

\author{
Quratull ain Abbas ${ }^{a}$, Ahsan Riaz ${ }^{\text {b }}$ \\ ${ }^{a}$ Lecturer, Government and Public Policy Department, National Defense University Islamabad, Pakistan \\ Phd Scholar, Political Science Department, Bahaudin Zakariya University Multan, Pakistan \\ Email: aniabbas@hotmail.com \\ ${ }^{\mathrm{b}}$ Assistant Professor, Department of Political Science, The Islamia University of Bahawalpur, Pakistan
}

\begin{tabular}{l}
\hline ARTICLE DETAILS \\
\hline History: \\
Accepted 25 May 2021 \\
Available Online June 2021 \\
\hline Keywords: \\
Threat Multiplier, Temperature, \\
Climate, States, Conflict \\
\\
JEL Classification: \\
K32, Q51 \\
\hline
\end{tabular}

DOI:

\begin{abstract}
Climate change, also called global warming, refers to the rise in the average surface temperature on Earth. Over the past century, earth's average temperature has risen by $1.5^{\circ} \mathrm{F}$, and is projected to rise 0.5 to $8.6^{\circ} \mathrm{F}$ over the next hundred years. These changes in the average temperature of the earth may lead to potentially dangerous shifts in climate and weather. Increased rainfall, decreased precipitation, augmented temperature, frequent heat waves, droughts and floods have likely to pose challenges for economic, social and geo-political security of states. Present study is an effort to understand the impacts produced by changing climate in social, economic and political spheres and its link with the emergence of violent conflicts. It further aims to investigate the relationship between National Security and Conflict however the main focus will be the domestic societies of under-developing countries. In order to address the objectives of this study, descriptive research approach has been applied. The validity of concept has been tested by qualitative analysis of the climatic variations on economic, social and geo-political spheres. The study finds out that climate change and economic stability are inextricably linked. The data of this study also suggested that the impacts of climate change are expected to act as a "Threat Multiplier " as a whole and can be more disastrous for the unstable regions thus resulting in shortage of food, water and other resources. It is thus concluded that scenario may lead to increased risks of conflicts among nations for control over the natural resources though climate change is unlikely to be a primary cause of conflict however it will remain an important factor in the emergence of conflict and it may also amplify the existing conflicts due to scarcity of resources.
\end{abstract}

(C) 2021 The authors. Published by SPCRD Global Publishing. This is an open access article under the Creative Commons Attribution-

NonCommercial 4.0

Corresponding author's email address: aniabbas@hotmail.com

\section{Introduction}

The changing patterns of weather related phenomena have given rise to global warming that has resulted in an overall change in climate. The growing economic and industrial growth has resulted in an 


\section{Review of Economics and Development Studies, Vol. 7 (2) 2021, 277 -286}

increase in greenhouse gases that has consequently resulted in an enormous increase in the intensity of $\mathrm{CO} 2$ in the atmosphere. This amplification has further led to an overall increase in the global temperatures thus resulting in further extreme patterns of weather. The rudiments of this prevailing outlandish are starvation, eruption of diseases, riots as well as violence and war. Droughts, storms, long persisting heat waves, wild fires, migrations, diseases, conflicts and extinction of various species have redefined the concept of national security for states. (Boon, K., Lovelace, 2012)

The protection of the nations as well as its citizens from all kinds of internal and external terrorization either by the use of military or any other diplomatic mean is known as national security however; with the transforming global scenario has redefined the concept. The episodes of 1973 oil crisis and 9/11 era has further transformed the concept of national security. This new notion of national security not only includes the defense of the physical borders but also encompasses the economic, political, social, environmental and other transnational threats like drug trafficking, epidemics, transgression or social prejudice. Currently, nations are striving hard to adopt such policies that can protect them from transnational threats specifically climate change.

\section{Literature Review}

In the past decade much research has focused on climate change impacts. According to research conducted by Yadigar Sekerci and Sergei Petrovskii, in the "Mathematical Modeling of Plankton-Oxygen Dynamics under the Climate Change", the increasing ocean temperatures could result in the Earth's oxygen levels to fall radically this could result in killing a huge number of humans and animals. Increasing temperatures will also impact the hydrological cycle by speeding it up thus leading to more evaporation and rain. (Sekerci, Y., \& Petrovskii, S. 2015) As reviewed by Robert Scribbler globally famines and droughts have already made half billion people to suffer and the rising temperatures shall further intensify the situation. (Hobday, A. J., \& Matear, R. J. 2020) A similar study has been conducted by EU commission; the report claimed that around 240 million people are suffering from the food shortages. In another study presented by Green Peace it is claimed that water shortages and famine has affected 330 million people alone in India. Likewise, rising temperature has led to the melting glaciers that have raised the sea levels, the phenomena is further explained by James Hansen an X- NASA researcher in July 2015 that sea levels are expected to rise 10 times more rapidly than predicted in the past. These impacts of climate changes are creating threats to the national security and it can be a cause of conflict as rightly pointed out by researchers. Internationally, the most persuasive work showing link between varying climate and conflict came from, Y. Burke he claims that there exists a link between rising temperatures and eruption of civil war. He thus concluded that frequency of civil war is directly proportional to the mounting temperature. According to him, in Africa increasing surface temperatures will produce a negative impact on agricultural output and economic performance, thus fuelling up the frequency of civil instability and up to some extent conflicts. Likewise, Hendrix and Glaser are of the view, that climate acts as a trigger and may give rise to conflicts at different level. The emerging connection between the conflict and climate has been well pointed out by the Security-Planning department as well as the US Center for Naval analysis, they claim climate change as a "Threat Multiplier" referring to the fact that it can not only produce impact but can also worsen the existing domestic, global as well as regional tensions and conflicts. Additionally, it has been predicted in Pentagon Quadrennial Defense Review that changing climate can act as an "Accelerant of instability or conflict". A similar vision has been cited by UK Defense review 2010 (US Department of Defense 2010), the emerging climatic changes can act as a nascent challenge for militaries as well as policy makers.

In spite of a series of well structured researches on climate verification and its linkages with national security and conflict some questions still remain unanswered. Although, the ability of the 
Review of Economics and Development Studies, Vol. 7 (2) 2021, 277 -286

changing climate to fuel up clashes or intensification of existing shakiness in some of the world's most vulnerable regions is now acknowledged in circles of national security even in the United States and many other nations of the world but research gaps still exists in many areas. For example, how Climate Change influence on economic, political and social spheres of nations and results in the emergence of conflicts, likewise how these spheres are interlinked in aggravating the origin of the ethnic conflicts at domestic level.

Present study is an effort to understand the impacts produced by changing climate in social, economic and political spheres and its link with the emergence of violent conflicts. It further aims to investigate the relationship between National Security and Conflict however the main focus shall be the domestic societies of under-developing countries.

\section{Research Design and theoretical Frame Work}

In contemplation to reach the ambition of the study the descriptive research has been followed as it aimed at casting light on current climate change issues and meant to find out its relation with national security and conflict. Qualitative and interpretative research methods have been used to find out answers how climate changes constitutes threat to national security and how these changes can be a cause of conflict. The soundness of concept is tested by scrutiny of data by implementing the political economy of climate change approach, the approach deals with analysis of climate change in perspective of political economy. Analysis of the study from perspective of political economy will help examine the relation between various stake holders like states as well as different interest groups at domestic level and global level. The approach also helps to find the grass root causes of the emergence of conflict at various levels.

For this purpose primary and secondary data collection techniques have been used. Books, scholarly articles, archival data and other internet resources along with the reports published by different related institutions have been used. Interviews of relevant personals of various Public and private institutes, like Pakistan Meteorological Department, Pakistan Agricultural Associations and Farmers.

\section{Analysis and Discussion}

The global order is not static, it is dynamic and with the passing time new changes can be seen in the economic, social and political spheres around the globe. Every great event around the globe has led to many new concepts and transformations in the world. Today, defending the sovereignty of government, political system, protection of society from both domestic and foreign aggressors, protection of economic and financial resources along with the market insecurities, preservation of energy and natural resources, protection of domestic affairs from recently emerging transnational threats, securing nations from cyber-crimes and many more are considered more important than typical military security. Consequently broadly speaking the concept of national security has broadened together with economic security, social security, political safety, human protection and environmental security. Environmental security is a concept with multiple meanings, environmental problems such as shortage of water, disruptions in energy supply or ruthless changes in climate has been regarded as transnational threats and can be a basis of conflict amongst states in near future.

Previously, changing climate was seldom regarded as a threat to national security or a contributing factor to the emergence of conflict, but in recent years with the changing concept of security, presupposition is changing as the dogma of "climate change " and "global warming" adheres to the national security. In other words, climate change is directly linked with the national interest, 
when the national interest is in danger it will pose threats to national security and when national security is in danger, it may indulge nations into conflict. In short, climate change is considered as an important trans-national factor behind existing and many upcoming conflicts amongst nations.

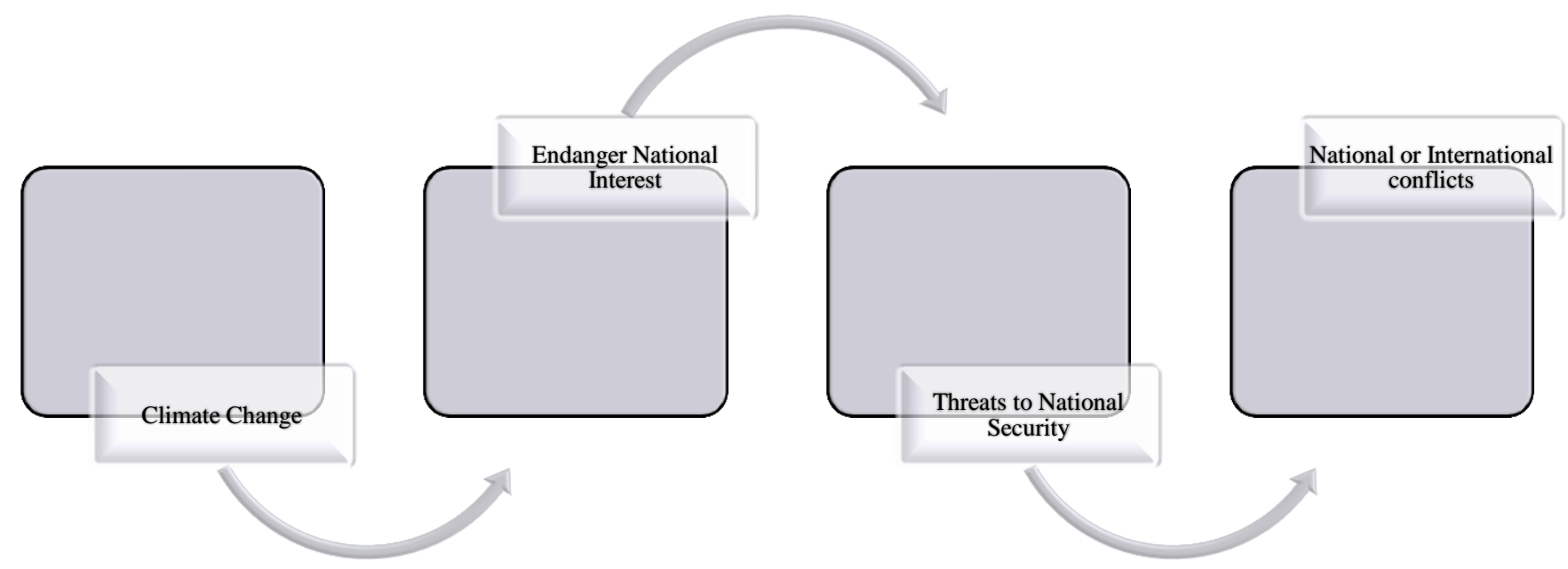

(Author's own compilation)

According to a research titled "Quantifying the Influence of Climate on Human Conflict" published in The American involvement for the Advancement of Science, 2013, there exists a statistical connection between emergence of conflicts and changing climate (Hsiang, S. M., Burke, M., \& Miguel, E. 2013). According to the research, increasing temperature and precipitation are interrelated with higher risks of social chaos, as well as individual violence.

The changing climate may lead to three main categories of conflict influencing three major sectors of any nation, "personal level or individual violent behavior and transgression," which includes killings, physical attack, rape and family aggression thus producing negative influence sociologically putting the society towards more negativity ; "intergroup violence and political instability," such as domestic hostilities, riots, racial aggression as well as territory invasions thus leading to a threat full environment politically even leading to crash of governments in severe cases ; and "institutional breakdowns or state level conflicts," such violence and conflicts may lead to strives over resources amongst nations thus creating hazards economically for a nation. (Addison, T. 2012) The impacts of climate change at these levels are felt equally in both developed and developing nations even the analysis of data from different developed and developing states like Brazil, Somalia, China or the United States, has shown clearly that the climate seems to be a vital factor in destruction of security and peace across societies thus these multiple vectors of climate change can result in a serious threat to the national security in economic, political and social aspects of state. 


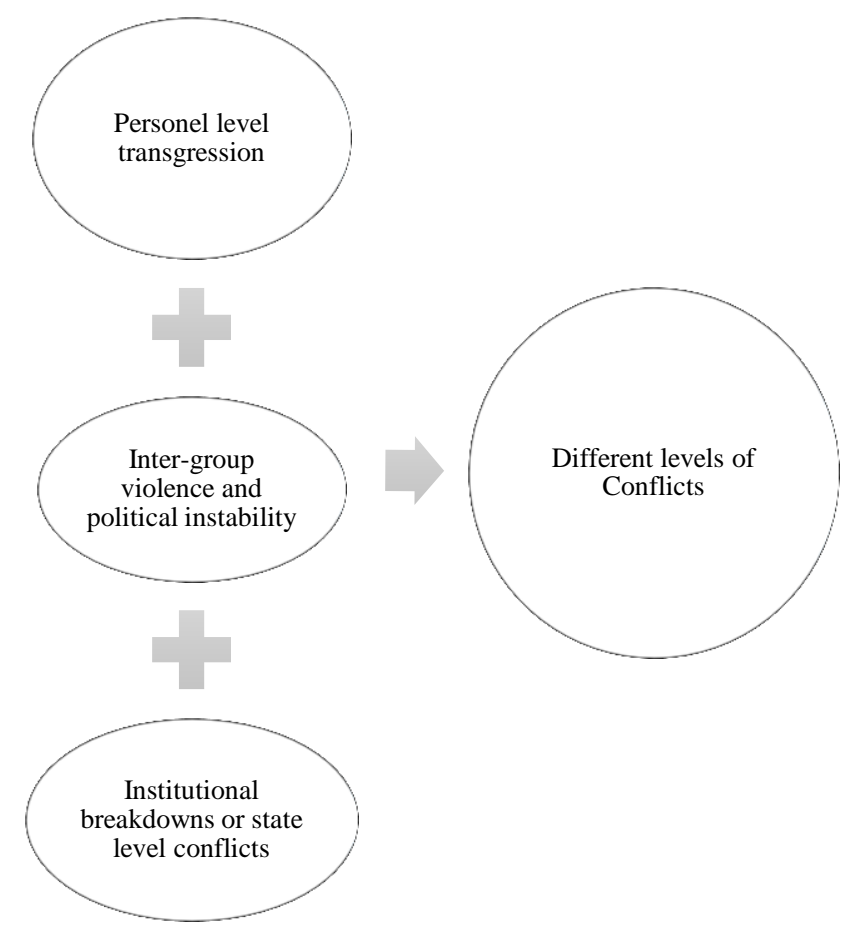

Three level of Conflicts as a consequence of Climatic Change (Author's own compilation)

An X- World Bank leading economist Lord Stern has analyzed the expenses and opportunities of global climate change in a report known as "The Stern Review". It has been concluded in the report that early strategies to control GHG emissions may outlay only $2 \%$ of the GDP however; the report projected a warning that any delay in devising strategies may elevate the economic costs up to $20 \%$ of the GDP. It will influence nations various economic sectors like agriculture, mining, forestry, fishing, infrastructure and energy security, consequently upsetting their economic system.

Climate change is about to produce the most profound influence in the field of agriculture (both arable and pastoral farming), in this respect agri-based economies will be more vulnerable as compared to economies having industry as their base, for instance African countries are more susceptible to various stresses of climate change, as it is estimated that around 250 million people (El-Hinnawi, E, 2011) are expected to go through water as well as food insecurities. A similar case can be seen in Pakistan whose major export is cotton, any disruption in cotton crop yield may directly affect the market economy of the country thus leading to less foreign exchange earnings and depressing balance of payment thus making country's economic security under further distress. Various climatic factors like increasing temperature and precipitation can prevent crop growth for example, in 2010 and 2012 high temperature at night affected corn crop across US. Similarly premature budding due to warm winters led to $\$ 220$ million losses of cherries in Michigan in 2012.( Zhang, D. D., Jim, C. Y., Lin, G. C., He, Y. Q., Wang, J. J., \& Lee, H. F, 2006) Likewise, high temperature may lead to more aridity in the atmosphere thus causing soil more drier, although irrigation has been used in many areas to overcome this issue but in most cases it has led to desertification of land .This situation makes less land available for agriculture thus causing a struggle amongst local communities for pastures and water, particularly in case of nomads. Likewise a similar anxiety has been highlighted by Suhrke in Sudan according to him, such expansions of desert does not be evident in a vacuum, but to a certain extent in a socioecological system, he explains by exemplifying nomadic pastoralists, who are gradually becoming restricted in their search for pastures and water. It has been exposed, that armed violence has been 
Review of Economics and Development Studies, Vol. 7 (2) 2021, 277 -286

increased amongst pastoralist groups and farmer's communities, and one reason might be the increasing infringement of Pastoralists towards irrigational fields for water as well as pasture. (Suhrke, A, 1997)

This study is analogous to safer world's view of northern Kenya and the perception presented by Walker on the Senegal's dry stretches, where disputes amongst pastoralist and farmers have given rise to brutal clashes. (Schneider, G., Gleditsch, N. P., \& Carey, S. C, 2010) Moreover, changed precipitation pattern i.e., high or less rainfall then requirement results in surface agricultural pollution, heavy rainfall may wipe away manure and fertilizers off of the farms and into nearby water body thus making water more polluted and less production of crop yields .A similar damage can be seen in case of pastoral farming , rising temperature, drought and desertification leads to threaten pastures and food supplies along with increased vulnerability to diseases, reduced fertility and less milk and meat production thus giving a setback to those nations whose major exports are live stock products or agri based products as in case of Pakistan. In short, low food production, desertification, droughts will eventually leads to resource depletion that can be cause of conflict at all levels.

Studies have shown that few climatic factors are found responsible for civil unrest in Syria as observed in a report titled, "Syria: Climate Change, Drought and Social Unrest," published in March 2012, from the "Center for Climate and Security". According to the report, the existing conflict in Syria has been associated to climate change up to some extent. According to the study presented by these authors, climate change has resulted in an internal displacement, rural disconnection and political instability that eventually contributed to the situation of civil war seen today in Syria. This study cites shortages of water, famine, crop-failures and displacement as the main contributing factors to Syria's civil war, furthermore farmlands of Syria has collapsed due to climate change. ( Femia, F., \& Werrell, C, 2012)

Another catastrophic climatic impact on economy will be the destruction of the infrastructure , rising coastal levels, floods, cyclones, tsunamis and many more has led to destruction of infrastructure in both developing and developed nations for instance, when the River Koshi which flows through the Eastern side of Terai region of Nepal flooded in summer 2008, it resulted in displacement of more than 6o,ooo people, the national highway was damaged, and crops were shattered badly. South Asia is the most vulnerable region; in fact most affected by the floods intricate ecological, humanitarian and security challenges. (Theisen, O. M., Holtermann, H., \& Buhaug, H, 2010) In this respect the most acute impact of climate change is in particular is felt by India and Bangladesh. In September 2012 floods displaced 1.5 million natives in the north eastern state of Assam, while in 2009; Cyclone Aila displaced 2.3 million inhabitants in India and approximately 850,000 in Bangladesh. Moreover, the sectors of Fishing , forestry, and tourism are badly affected due to such changes specifically those countries whose major exports are fishing and whose major foreign exchange earnings is through tourism, such economies are more vulnerable to climate change impacts.(Lapper, R, 2006) Economically, it has another influencing impact on the nations, since last few decades nations are trying to shift their energy usage from oil to other alternative sources like renewable sources of energy but all these alternative sources are exposed to the climate change. Moreover with the conditions of WTO it is becoming nearly impossible for struggling economies to compete the market under above mentioned situations. This scenario has endangered the nation's national security directly or indirectly and forced them towards a more conflict prone scenario.

Socially, "Migration" is the worst impact of Climate change specifically in the third world states like Bangladesh. It has been revealed that in 2008 agriculture has been main the occupation of around 


\section{Review of Economics and Development Studies, Vol. 7 (2) 2021, 277 -286}

1.4 billion population in third world countries however due to changing climatic influence, like increased food shortages and the reduction of employment opportunities and diminished farm-based activities has led to rapid outward migration. Although, Migration in itself is not the only destabilizing factor; it often payback to both the migrants and the states where they migrate however, accepting these migrants later becomes an issue for the states as these new comers are usually seen as a redundant burden. Such influx can result in ethnic sentimental clash within community, as in case of Assam and Bangladesh, the country is going through summer droughts, flooding and salination of the rivers at the coast. Consequently, about half a million inhabitants have been displaced within Bangladesh to the hill tracts of Chittagong and millions have migrated to India. Both the communities in Chittagong(Bangladesh) as well as the north-east Indian region, the region has faced social frictions and violent conflicts due to migration of people across the borders. In order to avoid such and other social havocs India has erected 2500 metres long barrier at the border. In other words buildup of climatic problems and issues in Bangladesh will in return influence India too. Added stressors of climate change and shifting migration patterns could be a security distress in areas of conflict in South Asia. Moreover, increased migration may lead to religious extremism as in case of Assam-Bengal. Moreover, such social movements amplify the assaults, rapes and murders leading to conflicts and wars amongst different ethnic groups. As a result of these rising insecurities, many psychological disorders may arise amongst the general public. Likewise when migration put pressure on land it results in competition over resources causing the origin of conflict amongst rural urban population secondly, it may give rise to social insecurities thus widening gap between rich and poor.

As a consequence of overall changing climate there seems an increase in domestic violence in India, Australia, US. Studies have shown that Tanzania has witnessed augmentation in assaults, rapes and murders particularly all throughout heat waves. There exists a correlation between increasing temperatures and larger conflicts, as higher temperatures make people more prone to aggression, racial clashes in Europe and South Asia as well as African civil wars are best examples.

Politically, it has direct impact on the institutions of the government as the individual level conflicts and civil war as a result of changing climate may leads to institutional inefficiency, even in some cases may lead to complete collapse of the system, changing climate may leads towards deteriorated relations amongst the states thus leading to failure of regionalization and regional interdependence. Pakistan and India are facing multiple conflicts but one of the most important is over water resource. With the passing time, changing climate is leading the region towards water scarcity thus giving rise to conflict over water. The main source of economic development either industry or agriculture is water and it is currently under severe influence of climate change. Globally this change of climate presents risks for South and South -East Asia and the main area for concern will be accessibility to the resources. Glaciers will be specifically under influence

The glaciers will be under influence of the climate change as their excessive melting before time will result in excessive water in some of the major rivers across the globe. In the Himalayan Basin, the increased rate of melting of the glacial areas will eventually result in an increase in the flow of water during spring season while on the other hand a low flow will be seen during the remaining seasons especially the summers. According to an estimate, the mass of the glaciers located in Himalayas has reduced to $1,628 \mathrm{sq} \mathrm{km}$ in 2007; while it was around 2,077 sq km in 1962 with a decline of around 21percent.(Gleditsch, N. P, 2011) This amplified rate in melting of glacier can produce two fold impacts like it may increase the run-off of the rivers similarly it may mount the avalanches outburst floods (GLOFs) at elevation. This situation will cause threat not only for the projects and dams at these rivers but it may also be a threat for future hydro projects in the area. If the present drift continued, water 


\section{Review of Economics and Development Studies, Vol. 7 (2) 2021, 277 -286}

bodies in Himalayan belt will soon go through amplification in the flood frequency. It may also lead to reduced flow during summer. Some chief rivers in Asia will specifically be under influence of climate change, like "The Ganges Basin (Nepal, India and Bangladesh); the Indus Basin (India and Pakistan); and the Mekong River (China, Burma, Thailand, Laos, Cambodia and Vietnam)". In case of Indus Basin, water is one of the foremost reasons of conflict amongst India and Pakistan. Although growing water insufficiency in the region have forced both states to sign a treaty in 1960, The Indus Water Treaty however an internal dissatisfaction prevails amongst both states. On the other hand Upper riparian state China requires a huge amount of water to sustain its rapidly increasing economic growth. A similar concern may be seen in case of Africa, due to increasing population growth and growing economies, and above all changing climate, riparian countries are taking one-sided actions to make water safe, while on the other hand they are not only potentially damaging the water bodies but it is also producing a negative impact on the relations among riparian states.

In short it will not be wrong to quote that climate change is an important component of nontraditional security challenges, after terrorism it is on nation's top agenda to be tackled as in case of South Asia. These changes are going to produce intense impacts on economic social and political spheres of nations, these spheres are interrelated, in other words impacts produced on one will be felt by all others for example, if agricultural production decreases it may lead to food shortages, directly affecting exports of an agri-based economy thus leading to economic backwardness on the other hand a sharp decline in food production will result in increased migration that will eventually produce social instability.

This social instability may lead to conflicts at domestic level thus making the institutional failure and affecting the nations politically. The consequences produced as a result of instability are subsequently severe and can rightly be called as a "security problem". These security problems are considered as grave challenge to the existence of nations and considered as a matter of national security and in severe cases may lead to conflict. In order to cope up with these challenges, nations need to use both military and non-military tools.The link of national security, origin of conflict and climate change is well explained by the following flow chart,

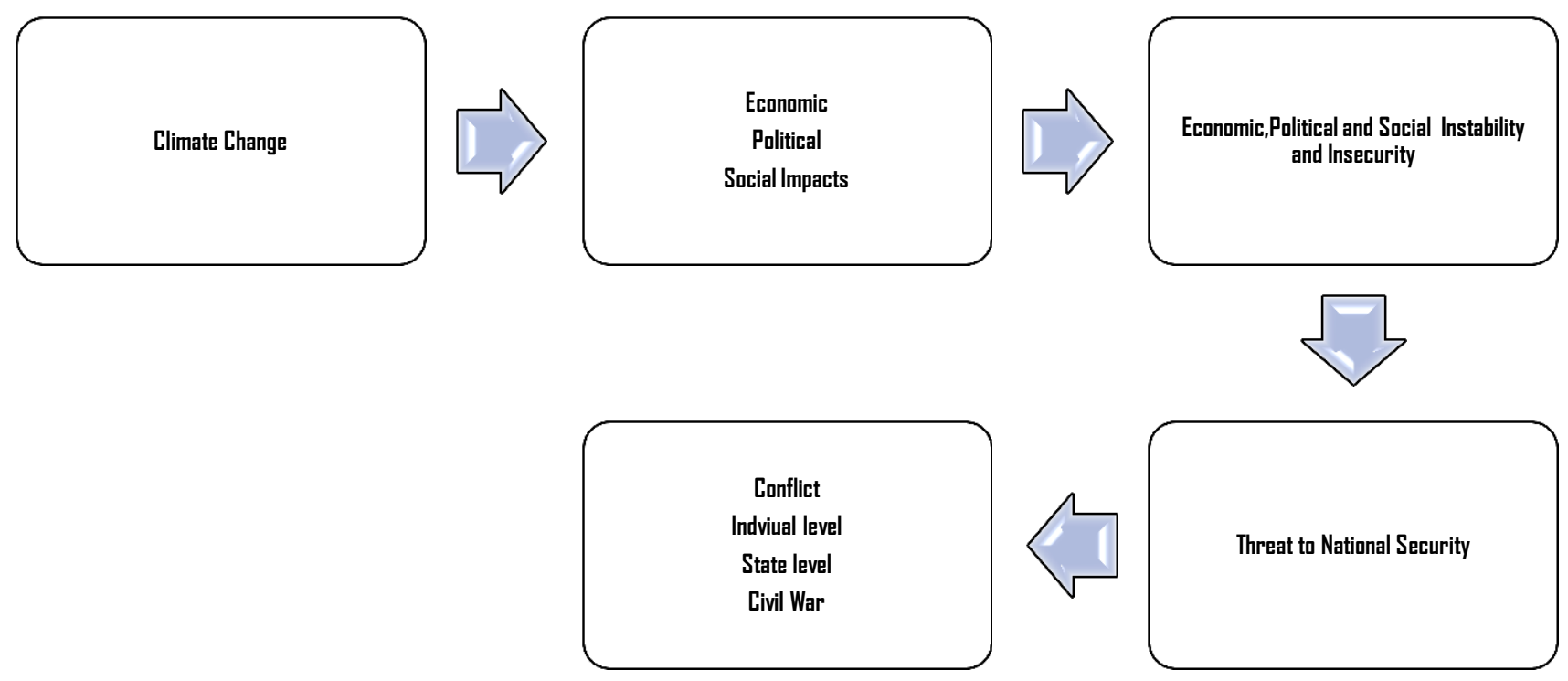

(Author's own compilation) 


\section{Conclusion}

Researches and studies over time have shown a connection between conflict and climate. Climate change not only fuel up the flames of social tension but it also contributes in the origin of conflict.

The link between conflict and climatic events is general and that its impact has been felt everywhere across history of humans, different regions of the globe, various kinds of conflicts and across all skeptical scales. Although it not true that all types of climatic events are the cause of all forms of conflicts but it can be strongly quoted it is one of the many factors that contribute to conflict.

In this scenario the conflict will be at all levels affecting all regions but the severity of impacts shall vary region to region for instance, poorer countries will be more vulnerable as compared to developed nations. Weak governance, poor infrastructure planning social chaos and corruption may lead the poor states to be the harsh target of climate change. Though this scenario will not be the sole cause of the conflict but it will surely aggravate the existing conflicts as in case of India and Pakistan in other words as mentioned earlier it will multiply the factors for current conflicts not only at international level but also at social levels.

Today climate change must be on top agenda of states as if timely steps would not be taken it may be disastrous for nation's especially underdeveloped and developing nations. In order to resolve this issue, nations must move hand in hands to deal with this global issue specifically third world for example issues related to water basins in South Asia and Africa has already been resolved with international cooperation. Secondly, developing countries must improve their institutional structures and must undergo progress in their governance process. Thirdly, nations must think over an economic shift as in case of India and China, they are gradually focusing on a shift from agriculture to industrial sector as industry consumes much less water and other natural inputs as compared to agriculture , this shift might be helpful for Asian countries whose main source of income is agri-based economy. Fourthly, states must possess better technological strengths and more capability in finances to overcome these climatic changes. sFinally negotiation process must be at its fastest pace by both developed and third world countries as this is a havoc that needs cooperation at all level.

\section{References}

Addison, T. (2012). Human security report 2009/2010: The causes of peace and the shrinking costs of war.

Boon, K., Lovelace, D., \& Huq, A. (2012). Terrorism: Commentary on Security Documents Index IV (Vol. 101). Oxford University Press, USA.

El-Hinnawi, E. (2011). The intergovernmental panel on climate change and developing countries. The Environmentalist, 31(3), 197-199.

Femia, F., \& Werrell, C. (2012). Syria: Climate change, drought and social unrest. The Center for Climate and Security, 29.

Gleditsch, N. P. (2011, January). Regional conflict and climate change. In Workshop on Research on Climate Change Impacts and Associated Economic Damages.

Hendrix, C. S., \& Glaser, S. M. (2007). Trends and triggers: Climate, climate change and civil conflict in Sub-Saharan Africa. Political geography, 26(6), 695-715.

Hobday, A. J., \& Matear, R. J. (2020). The impact of climate change on oceans: physical, chemical and biological responses. In Research Handbook on Climate Change, Oceans and Coasts. 
Edward Elgar Publishing.

Hobday, A. J., \& Matear, R. J. (2020). The impact of climate change on oceans: physical, chemical and biological responses. In Research Handbook on Climate Change, Oceans and Coasts. Edward Elgar Publishing.

Hsiang, S. M., Burke, M., \& Miguel, E. (2013). Quantifying the influence of climate on human conflict. Science, 341(6151), 1235367.

Lapper, R. (2006). Living with Hugo: US Policy Toward Hugo Chávez's Venezuela (No. 20). Council on Foreign Relations Press.

Schneider, G., Gleditsch, N. P., \& Carey, S. C. (2010). Exploring the past, anticipating the future: A symposium. International Studies Review, 12(1), 1-7.

Sekerci, Y., \& Petrovskii, S. (2015). Mathematical modelling of spatiotemporal dynamics of oxygen in a plankton system. Mathematical Modelling of Natural Phenomena, 10(2), 96-114.

Suhrke, A. (1997). Environmental degradation, migration, and the potential for violent conflict. In Conflict and the Environment (pp. 255-272). Springer, Dordrecht.

Theisen, O. M., Holtermann, H., \& Buhaug, H. (2010). Drought, political exclusion, and civil war. Int Secur, 36, 79-106.

US department of Defense , Quadrennial Defense Review Pentagon 2010. https://www.defense.gov/News/Special-Reports/QDR

Zhang, D. D., Jim, C. Y., Lin, G. C., He, Y. Q., Wang, J. J., \& Lee, H. F. (2006). Climatic change, wars and dynastic cycles in China over the last millennium. Climatic Change, 76(3-4), 459-477. 